\title{
Crystalline Structure of Potassium Holmium Double Tungstate
}

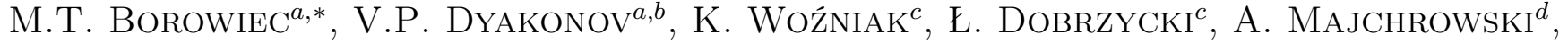

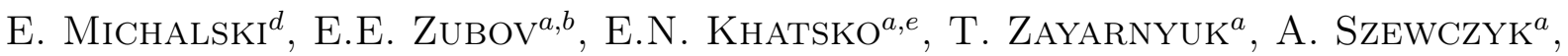 \\ M.U. Gutowska ${ }^{a}$, A.I. Rykova ${ }^{e}$, M. BArański ${ }^{a}$, V. Domukhovski ${ }^{a}$, V. Shtyrkhunova ${ }^{b}$, \\ P. IWANOWSKI ${ }^{a}$, J. ŻMIJA ${ }^{d}$ AND H. SZYMCZAK ${ }^{a}$ \\ ${ }^{a}$ Institute of Physics, Polish Academy of Sciences, al. Lotników 32/46, 02-668 Warsaw, Poland \\ ${ }^{b}$ A.A. Galkin Donetsk Institute for Physics and Engineering, National Academy of Sciences of Ukraine \\ 72 R. Luxemburg str., Donetsk 83114, Ukraine \\ ${ }^{c}$ Chemistry Department, Warsaw University, L. Pasteura 1, 02-093 Warsaw, Poland \\ ${ }^{d}$ Institute of Applied Physics, Military University of Technology, S. Kaliskiego 2, 00-908 Warsaw, Poland \\ ${ }^{e}$ Institute for Low Temperature Physics and Engineering of the NAS of Ukraine, 47 Lenin Ave., Kharkov, Ukraine
}

(Received December 13, 2010; in final form March 14, 2011)

\begin{abstract}
The potassium holmium double tungstate was prepared by using top seeded solution growth technique. Structural investigations have been performed at room temperature. The $\mathrm{KHo}\left(\mathrm{WO}_{4}\right)_{2}$ single crystal belongs to the monoclinic space group $C 2 / c$ with the unit-cell parameters: $a=10.624(2) \AA, b=10.352(2) \AA, c=7.5434(15) \AA$, $\beta=130.78(3)^{\circ}$, and $Z=4$. The atomic coordinates, isotropic and anisotropic displacement parameters and interionic distances for the studied structure were determined.
\end{abstract}

PACS: 61.66.Fn

\section{Introduction}

The monoclinic $\mathrm{KHo}\left(\mathrm{WO}_{4}\right)_{2}$ (KHoW) single crystals were grown by using the top seeded solution growth (TSSG) method as described in Ref. [1]. The rare-earth double tungstates undergo the irreversible structural phase transition at temperature slightly below their melting points. This phenomenon does not allow to obtain the low temperature phases of these compounds by means of the Czochralski method despite their congruent melting. To diminish temperature of crystallization below the phase transition temperature the high temperature solution growth (HTSG) and TSSG techniques were used [1].

The results of magnetic measurements of potassium holmium double tungstate are described in Ref. [2].

In this paper, the results of X-ray diffraction measurements of potassium holmium double tungstate are presented, and the crystal structure parameters of $\mathrm{KHo}\left(\mathrm{WO}_{4}\right)_{2}$ were determined.

* corresponding author; e-mail: borow@ifpan.edu.pl

\section{Experimental}

$\mathrm{X}$-ray diffraction measurements were performed for a prismatic $\mathrm{KHo}\left(\mathrm{WO}_{4}\right)_{2}$ single crystal with the dimensions of $0.35 \times 0.25 \times 0.16 \mathrm{~mm}^{3}$ using a Kuma $\mathrm{KM} 4 \mathrm{CCD}$ four-circle $\kappa$-axis diffractometer with graphite-monochromated Mo $K_{\alpha}$ radiation as well as omega scan technique. The crystal was positioned at $65 \mathrm{~mm}$ from the KM4CCD camera. The collection of data for KHoW was performed with accelerating voltage reduced to $34.2 \mathrm{kV}$ to eliminate evident " $\lambda / 2$ contamination" effect $[3,4]$. The data were corrected for the Lorentz and polarization effects. Analytical absorption correction was applied with shape optimization procedure based on reflections 20 times higher than their error. Data reduction and analysis were carried out with the Kuma Diffraction suit of programs.

The $2 \theta$ range of data collection was from $8^{\circ}$ to $100^{\circ}$ with $1^{\circ}$ interval, and the unit cell parameters are based on 10000 reflections, while the structure is based on reflections up to $2 \theta$ equal to $62^{\circ}$.

The structure was solved by direct methods and was refined using SHELXL [4]. The refinement was based on $F^{2}$ for all reflections except those with very nega- 
tive $F^{2}$. Scattering factors were taken from tables 6.1.1.4 and 4.2.4.2 presented in Ref. [5].

All the samples studied had identical crystallographic structure, chemical and physical properties, because they have been cut out of the initial crystal.

\section{Structural studies}

The crystalline data regarding the KHoW structure are given in Table I together with the refinement details. Fractional atomic coordinates, anisotropic displacement parameters and selected interatomic parameters are presented in Tables II and III, respectively (supplementary materials).

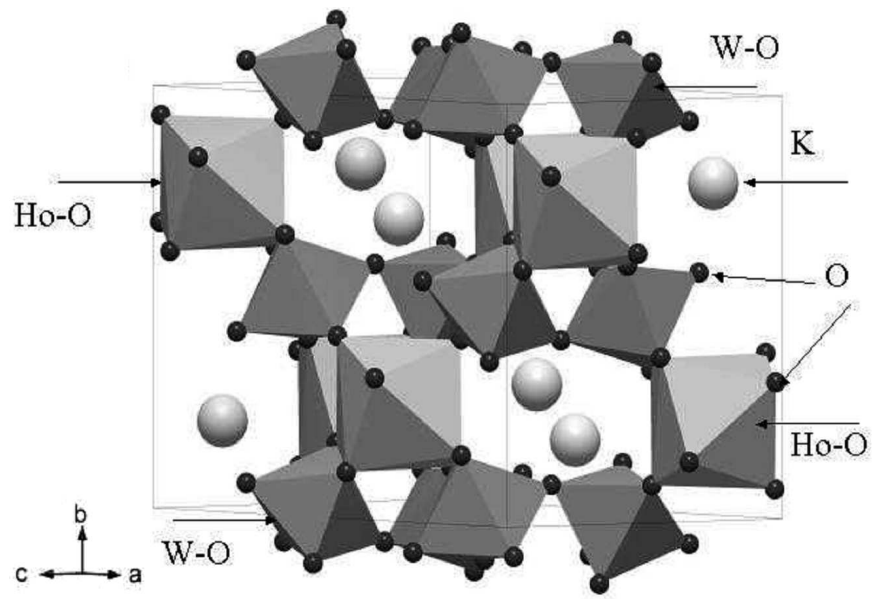

Fig. 1. The unit cell contents $\mathrm{W}$ and Ho polyhedra.

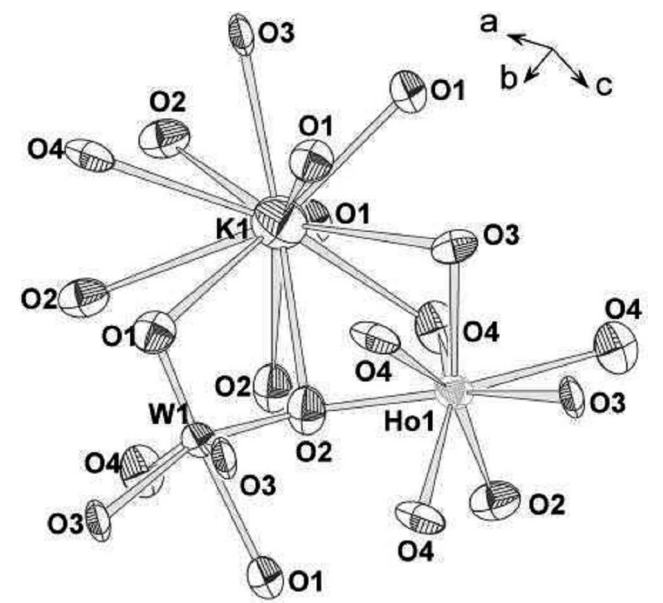

Fig. 2. Thermal ellipsoids with probability factor equal to $99 \%$.

The coordination figures of $\mathrm{W}, \mathrm{Ho}$ and $\mathrm{K}$ cations are shown in Figs. 1-3.

The unit-cell parameters obtained in this paper (Table I) are $a=10.624(2) \AA, b=10.352(2) \AA, c=$

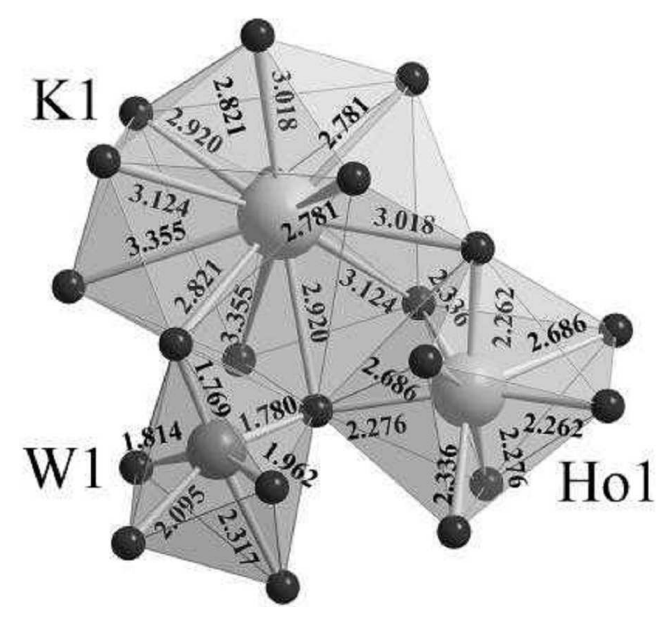

Fig. 3. Ho, K and $\mathrm{W}$ polyhedra with marked distances to ligands.

TABLE I

Crystal data and structure refinement for KHoW.

\begin{tabular}{l|l}
\hline \hline Empirical formula & $\mathrm{HoKO}_{8} \mathrm{~W}_{2}$ \\
Formula weight & 699.73 \\
Temperature & $293(2) \mathrm{K}$ \\
Wavelength & $0.71073 \AA$ \\
Crystal system, space group & monoclinic, $C 2 / c$ \\
Unit cell dimensions & $a=10.624(2) \AA, \alpha=90^{\circ}$, \\
& $b=10.352(2) \AA, \beta=130.78(3)^{\circ}$, \\
& $c=7.5434(15) \AA, \gamma=90^{\circ}$ \\
Volume & $628.2(2) \AA^{3}$ \\
Z, calculated density & $4,7.398 \mathrm{mg} \mathrm{cm}^{-3}$ \\
Absorption coefficient & $49.671 \mathrm{~mm}^{-1}$ \\
$F(000)$ & 1192
\end{tabular}

7.5434(15) $\AA, \beta=130.78(3)^{\circ}$, with $Z=4$ and space group $C 2 / c$.

As is seen in Table II, $\mathrm{K}$ and Ho ions occupy special positions (4e according to the Wyckoff notation in $C 2 / c$ space group, local symmetry of these ions is $C_{2}$ in the Schoenflies notation), while W1 cation occupies a general position, and its $y$ coordinate is very close to $1 / 2$.

TABLE II

Fractional atomic coordinates and equivalent isotropic displacement parameters $\left(\times 10^{3} \AA^{2}\right)$.

\begin{tabular}{c|c|c|c|c|c}
\hline \hline & $\begin{array}{c}\text { Wyckoff } \\
\text { position }\end{array}$ & $x$ & $y$ & $z$ & $U(\mathrm{eq})$ \\
\hline $\mathrm{Ho}(1)$ & $4 \mathrm{e}$ & 1.0000 & $0.7717(1)$ & 0.7500 & $7(1)$ \\
$\mathrm{W}(1)$ & $8 \mathrm{f}$ & $0.8039(1)$ & $0.4999(1)$ & $0.7642(1)$ & $5(1)$ \\
$\mathrm{K}(1)$ & $4 \mathrm{e}$ & 1.0000 & $0.7991(3)$ & 0.2500 & $15(1)$ \\
$\mathrm{O}(1)$ & $8 \mathrm{f}$ & $0.9765(6)$ & $0.3913(5)$ & $1.0304(8)$ & $7(1)$ \\
$\mathrm{O}(2)$ & $8 \mathrm{f}$ & $0.8100(6)$ & $0.4251(5)$ & $0.5592(9)$ & $9(1)$ \\
$\mathrm{O}(3)$ & $8 \mathrm{f}$ & $0.6259(6)$ & $0.4203(5)$ & $0.6885(8)$ & $9(1)$ \\
$\mathrm{O}(4)$ & $8 \mathrm{f}$ & $0.7258(6)$ & $0.6571(5)$ & $0.6261(8)$ & $10(1)$
\end{tabular}


TABLE III

Anisotropic displacement parameters (ADP) $\left(\times 10^{3} \AA^{2}\right)$.

\begin{tabular}{c|c|c|c|c|c|c}
\hline \hline & $U(11)$ & $U(22)$ & $U(33)$ & $U(23)$ & $U(13)$ & $U(12)$ \\
\hline $\mathrm{Ho}(1)$ & $8(1)$ & $6(1)$ & $6(1)$ & 0 & $4(1)$ & 0 \\
$\mathrm{~W}(1)$ & $5(1)$ & $6(1)$ & $4(1)$ & $1(1)$ & $2(1)$ & $0(1)$ \\
$\mathrm{K}(1)$ & $13(1)$ & $15(1)$ & $12(1)$ & 0 & $7(1)$ & 0 \\
$\mathrm{O}(1)$ & $6(2)$ & $7(2)$ & $7(2)$ & $0(2)$ & $4(2)$ & $-3(2)$ \\
$\mathrm{O}(2)$ & $9(2)$ & $7(2)$ & $10(2)$ & $1(2)$ & $7(2)$ & $2(2)$ \\
$\mathrm{O}(3)$ & $7(2)$ & $12(3)$ & $7(2)$ & $1(2)$ & $3(2)$ & $-1(2)$ \\
$\mathrm{O}(4)$ & $9(2)$ & $8(3)$ & $9(2)$ & $4(2)$ & $5(2)$ & $2(2)$ \\
\hline
\end{tabular}

Symmetry transformations used to generate equivalent atoms: $\# 1 x,-y+1, z-1 / 2, \# 2-x+2,-y+1,-z+2$, $\# 3 x+1 / 2, y+1 / 2, z, \# 4-x+3 / 2, y+1 / 2,-z+3 / 2$, $\# 5 x+1 / 2,-y+3 / 2, z+1 / 2, \# 6-x+3 / 2,-y+3 / 2$, $-z+1, \# 7-x+2, y,-z+3 / 2, \# 8 x, y, z+1, \# 9 x$, $-y+1, z+1 / 2, \# 10 x-1 / 2, y-1 / 2, z, \# 11-x+2,-y+1$, $-z+1, \# 12-x+3 / 2, y+1 / 2,-z+1 / 2, \# 13 x+1 / 2$, $-y+3 / 2, z-1 / 2$

This location influences on thermal motions (Table III) of this atom - the off-diagonal of the atomic displacement parameters (ADP) terms are almost equal to zero (within the experimental error: see $\mathrm{U}(23)$ and $\mathrm{U}(12)$ in Table III).

There are three kinds of polyhedra in KHoW structure, depending on the central cation, namely, octahedron, dodecahedron and icosahedron around $\mathrm{W}$, Ho and $\mathrm{K}$ ions, respectively (Fig. 3).

The unit cell contains four formula units. The structure of KHoW belongs to the chain-layered systems. The layers of $\mathrm{HoW}_{2} \mathrm{O}_{8}$ separated by $\mathrm{K}-\mathrm{O}$ polyhedra form chains along the $a c$ plane. Eight oxygen ions surrounding the $\mathrm{Ho}^{3+}$ ion form a dodecahedron in which two oxygen ions are spaced at a greater distance from the rare earth ion than the other six. The oxygen and tungstate are located at common positions. The $\mathrm{WO}_{4}^{2-}$ octahedrons compose layers perpendicular to the $b$ direction (Fig. 1).

\section{Acknowledgments}

This work was supported by EU project DT-CRYS, NMP3-CT-2003-505580, by Polish State Committee on Science (KBN) (decision of project No. $72 /$ E- $67 / \mathrm{SPB} / 6$. PR/DIE 430/2004-2006).

\section{References}

[1] A. Majchrowski, M.T. Borowiec, E. Michalski, J. Zmija, V.P. Dyakonov, H. Szymczak, T. Zayarnyuk, M. Barański, Cryst. Res. Technol. 36, 283 (2001); A. Majchrowski, M.T. Borowiec, E. Michalski, J. Cryst. Growth 264, 201 (2004).

[2] M.T. Borowiec, E.N. Khatsko, V.P. Dyakonov, A.I. Rykova, A. Majchrowski, T. Zayarnyuk, Cent. Eur. J. Phys. 9, 260 (2011)

[3] K. Kirshbaum, A. Martin, A. Pinkerton, J. Appl. Crystallogr. 30, 514 (1997); G.M. Sheldrick, Acta Crystallogr. A 46, 467 (1990).

[4] G.M. Sheldrick, SHELXL93, Program for the Refinement of Crystal Structures, Univ. of Göttingen, Germany.

[5] International Tables for Crystallography, Vol. C, Kluwer, Dordrecht 1992. 